\title{
Programa Saúde da Família
}

Departamento de Atenção Básica - Secretaria de Políticas de Saúde 


\section{Programa Saúde da Família}

Departamento de Atenção Básica - Secretaria de Políticas de Saúde

A partir da promulgação da Constituição Federal em 1988, foram definidas como diretrizes do Sistema Único de Saúde (SUS) a universalização, a eqüidade, a integralidade, a descentralização, a hierarquização e a participação da comunidade. Ao ser desenvolvido sobre esses princípios, o processo de construção do Sistema Único de Saúde visa reduzir o hiato ainda existente entre os direitos sociais garantidos em lei e a capacidade efetiva de oferta de ações e serviços públicos de saúde à população brasileira.

Apesar de esses princípios ainda não terem sido atingidos em sua plenitude, é impossível negar os avanços obtidos na última década no processo de consolidação do SUS, dentre os quais se destaca a descentralização com efetiva municipalização.

O modelo assistencial ainda predominante no país caracteriza-se pela prática "hospitalocêntrica", pelo individualismo, pela utilização irracional dos recursos tecnológicos disponíveis e pela baixa resolubilidade, gerando alto grau de insatisfação para todos os partícipes do processo - gestores, profissionais de saúde e população que utiliza os serviços.

Como consequiência, o bom senso milenar do "prevenir para não remediar" foi sendo reescrito com o abandono da prevenção e promoção da saúde em todas as suas dimensões.

Sob esse raciocínio, a rede básica de saúde, constituída pelos postos, centros ou unidades básicas de saúde, passou a ser assessória e desqualificada. Com isso, perdeu seu potencial de resultados, alimentando a própria lógica que a excluía de antemão. O que era para ser básico se tornou descartável e o topo da cadeia de atenção se transformou em porta de entrada.

Essa situação não se consubstanciaria se não houvesse o mínimo de resultados. No entanto, a síntese desse quadro é um modelo caro, ineficiente e desumano, que degrada a prática profissional e não atende às necessidades da população.

Ao longo dos anos, diversas pesquisas indicaram que unidades básicas de saúde, funcionando adequadamente, de forma resolutiva, oportuna e humanizada, são capazes de resolver, com qualidade, cerca de $85 \%$ dos problemas de saúde da população. $\mathrm{O}$ restante das pessoas precisará, em parte, de atendimento em ambulatórios de especialidades e apenas um pequeno número necessitará de atendimento hospitalar.

Analisando todo esse contexto e visando, enquanto estratégia setorial, a reorientação do modelo assistencial brasileiro, o Ministério da Saúde assumiu, a partir de 1994, como resposta intencional à essa conjuntura, a implantação do Programa Saúde da Família-PSF.

Em alguns contextos, ela se motivou mais pelo resgate de valores profissionais; em outros, pela capacidade de melhorar os indicadores de saúde e reordenar o modelo assistencial.

\section{O programa saúde da família}

Ao priorizar a atenção básica, o PSF não faz uma opção econômica pelo mais barato, nem técnica pela simplificação, nem política por qualquer forma de exclusão. A tecnologia, é bom que se reafirme, é uma conquista que o setor saúde entende como fundamental para o sistema, mas que vem sendo utilizada de forma excludente, deixando de fora boa parcela da população. O PSF não é uma peça isolada do sistema de saúde, mas um componente articulado com todos os níveis. Dessa forma, pelo melhor conhecimento da clientela e pelo acompanhamento detido dos casos, o programa permite ordenar os encaminhamentos e racionalizar o uso da tecnologia e dos recursos terapêuticos mais caros. O PSF não isola a alta complexidade, mas a coloca articuladamente a disposição de todos. Racionalizar o uso, nesse sentido, é democratizar o acesso.

Com base nessas premissas, o Programa Saúde da Família representa tanto uma estratégia para reverter a forma atual de prestação de assistência à saúde como uma proposta de reorganização da atenção básica como eixo de reorientação do modelo assistencial, respondendo a uma nova concepção de saúde não mais centrada somente na assistência à doença mas, sobretudo, na promoção da qualidade de vida e intervenção nos fatores que a colocam em risco - pela incorporação das ações programáticas de uma forma mais abrangente e do desenvolvimento de ações 
intersetoriais. Caracteriza-se pela sintonia com os princípios da universalidade, eqüidade da atenção e integralidade das ações. Estrutura-se, assim, na lógica básica de atenção à saúde, gerando novas práticas e afirmando a indissociabilidade entre os trabalhos clínicos e a promoção da saúde.

Assim, ao encaminhar os pacientes com mais garantia de referência e menos desperdício, o Programa Saúde da Família amplia o acesso de todos aos benefícios tecnológicos.

O modelo de atenção preconizado pelo Saúde da Família já foi testado em vários países, com contextos culturais de diferentes dimensões e níveis diferenciados de desenvolvimento socioeconômico, como por exemplo Canadá, Reino Unido e Cuba, resolvendo mais de $85 \%$ dos casos - o percentual restante destina-se a unidades mais complexas. Além do mais, o programa permite uma forte integração entre o Ministério, as secretarias estaduais, os municípios, a comunidade local e outros parceiros, em benefício de todos.

Por seus princípios, o Programa Saúde da Família é, nos últimos anos, a mais importante mudança estrutural já realizada na saúde pública no Brasil. Junto ao Programa dos Agentes Comunitários de Saúde - com o qual se identifica cada vez mais - permite a inversão da lógica anterior, que sempre privilegiou o tratamento da doença nos hospitais. Ao contrário, promove a saúde da população por meio de ações básicas, para evitar que as pessoas fiquem doentes. Porém, se o programa restringir-se apenas à atenção básica, fracassará. A aposta do Brasil é no SUS, na atenção integral e em todos os níveis de complexidade.

A estratégia do PSF propõe uma nova dinâmica para a estruturação dos serviços de saúde, bem como para a sua relação com a comunidade e entre os diversos níveis e complexidade assistencial. Assume o compromisso de prestar assistência universal, integral, equânime, contínua e, acima de tudo, resolutiva à população, na unidade de saúde e no domicílio, sempre de acordo com as suas reais necessidades - além disso, identifica os fatores de risco aos quais ela está exposta, neles intervindo de forma apropriada.

Não apenas as unidades básicas, mas todo o sistema deverá estar estruturado segundo a lógica da estratégia em questão, pois a continuidade da atenção deve ser garantida pelo fluxo contínuo setorial, sem solução de continuidade nesse processo. A unidade básica de saúde, sob a estratégia da Saúde da Família, deve ser a porta de entrada do sistema local de saúde, mas a mudança no modelo tradicional exige a integração entre os vários níveis de atenção.
O PSF representa ações combinadas a partir da noção ampliada de saúde - que engloba tudo aquilo que possa levar a pessoa a ser mais feliz e produtiva - e se propõe a humanizar as práticas de saúde, buscando a satisfação do usuário pelo estreito relacionamento dos profissionais com a comunidade, estimulando-a ao reconhecimento da saúde como um direito de cidadania e, portanto, expressão e qualidade de vida.

Uma das principais estratégias do Saúde da Família é sua capacidade de propor alianças, seja no interior do próprio sistema de saúde, seja nas ações desenvolvidas com as áreas de saneamento, educação, cultura, transporte, entre outras. Por ser um projeto estruturante, deve provocar uma transformação interna do sistema, com vistas à reorganização das ações e serviços de saúde. Essa mudança implica na ruptura da dicotomia entre as ações de saúde pública e a atenção médica individual, bem como entre as práticas educativas e assistenciais.

Configura, também, uma nova concepção de trabalho, uma nova forma de vínculo entre os membros de uma equipe, diferentemente do modelo biomédico tradicional, permitindo maior diversidade das ações e busca permanente do consenso. Sob essa perspectiva, o papel do profissional de saúde é aliar-se à família no cumprimento de sua missão, fortalecendo-a e proporcionando o apoio necessário ao desempenho de suas responsabilidades, jamais tentando substituí-la.

Tal relação de trabalho, baseada na interdisciplinaridade e não mais na multidisciplinaridade, associada à não-aceitação do refúgio da assistência no positivismo biológico, requer uma nova abordagem que questione as certezas profissionais e estimule a permanente comunicação horizontal entre os componentes de uma equipe.

Um dos principais objetivos é gerar novas práticas de saúde, nas quais haja integração das ações clínicas e de saúde coletiva. Porém, não se pode conceber a organização de sistemas de saúde que conduzam à realização de novas práticas sem que, de forma concomitante, se invista em uma nova política de formação e num processo permanente de capacitação dos recursos humanos.

Para que essa nova prática se concretize, faz-se necessária a presença de um profissional com visão sistêmica e integral do indivíduo, família e comunidade, um profissional capaz de atuar com criatividade e senso crítico, mediante uma prática humanizada, competente e resolutiva, que envolve ações de promoção, de proteção específica, assistencial e de rea- 
bilitação. Um profissional capacitado para planejar, organizar, desenvolver e avaliar ações que respondam às reais necessidades da comunidade, articulando os diversos setores envolvidos na promoção da saúde. Para tanto, deve realizar uma permanente interação com a comunidade, no sentido de mobilizála, estimular sua participação e envolvê-la nas atividades - todas essas atribuições deverão ser desenvolvidas de forma dinâmica, com avaliação permanente, pelo acompanhamento de indicadores de saúde da área de abrangência.

Entretanto, os sistemas de saúde não dispõem, hoje, de um número satisfatório de profissionais qualificados com esse novo perfil. Consciente dessa necessidade, o Ministério da Saúde, pelo Departamento de Atenção Básica da Secretaria de Políticas de Saúde, tem investido na formação de Pólos de Capacitação, Formação e Educação Continuada em Saúde da Família, com o objetivo de articular o ensino e o serviço, estimulando-os a reformarem seus cursos de graduação e a implantarem programas de pós-graduação (especialização e residência em saúde da família) com vistas a essa nova realidade - o que vem sendo respondido de forma sensível pelas faculdades e escolas de saúde de todo o país.

Nos últimos dois anos, foram investidos $\mathrm{R} \$ 12,4 \mathrm{mi}$ lhões para a instalação dos Pólos de Capacitação, Formação e Educação Continuada em Saúde da Família, e 54 instituições universitárias já estão envolvidas nesses projetos de capacitação e formação dos novos profissionais de saúde necessários. Esses esforços têm sido enviados no sentido de apoiar a formação profissional em nível de graduação, as pesquisas e, ainda, a constituição de programas de capacitação em serviço, num diálogo permanente entre as universidades e o setor público de prestação de serviços. É importante ressaltar que esse processo visa, também, a abertura de novos postos de trabalho.

\section{Financiamento}

A NOB 01/96, do Ministério da Saúde, vem contribuindo para a consolidação do programa, pois modificou a lógica de financiamento (anteriormente baseada na produção de serviços) passando a estabelecer o pagamento em função da cobertura populacional e introduzindo o incentivo do Programa Saúde da Família, além de outros mecanismos técnico-gerenciais.

Para o PSF, a Portaria n ${ }^{\circ} 1.329$, de 12.11.99, estabelece que, de acordo com a faixa de cobertura, os municípios passam a receber incentivos diferenciados, conforme demonstra a tabela a seguir:
Faixa de cobertura populacional e valores anuais do incentivo financeiro por equipe

\begin{tabular}{ccc}
\hline $\begin{array}{c}\text { Faixas de } \\
\text { cobertura }\end{array}$ & $\begin{array}{c}\text { Faixas de } \\
\text { Cobertura populacional } \\
\text { em \% }\end{array}$ & $\begin{array}{c}\text { Valor do incentivo } \\
\text { por equipe/ano } \\
\text { (em R } \$ 1,00)\end{array}$ \\
\hline 1 & 0 a 4,9 & 28.008 \\
2 & 5 a 9,9 & 30.684 \\
3 & 10 a 19,9 & 33.360 \\
4 & 20 a 29,9 & 38.520 \\
5 & 30 a 39,9 & 41.220 \\
6 & 40 a 49,9 & 44.100 \\
7 & 50 a 59,9 & 47.160 \\
\hline
\end{tabular}

A diferenciação existente nos valores dos incentivos deve-se ao fato de que quanto maior o número de pessoas cobertas pelo PSF, maior o seu impacto. Existe, ainda, um incentivo adicional para a implantação de novas equipes, num valor de $\mathrm{R} \$ 10.000$ /equipe, pagos em duas parcelas.

As diretrizes programáticas do PSF já são bem conhecidas. A reorganização da atenção à saúde implica numa reordenação da própria lógica de montagem das equipes. Essas equipes devem ser compostas por, no mínimo, um médico de família, um enfermeiro, um auxiliar de enfermagem e cinco a seis agentes comunitários de saúde - outros profissionais, tais como psicólogos, dentistas, fisioterapeutas, por exemplo, poderão ser incorporados de acordo com as características e demandas dos serviços locais de saúde. Cada equipe é responsável pelo acompanhamento de, no máximo, mil famílias ou 4.500 pessoas que residam ou trabalhem no território de responsabilidade da unidade de saúde, agora denominada "Unidade Básica de Saúde da Família".

Um dos caracteres de diferenciação desse processo é que os profissionais das equipes de saúde devem residir no município onde atuam, trabalhando em regime de dedicação integral. Por sua vez, para garantir a vinculação e identidade cultural com as famílias sob sua responsabilidade, os agentes comunitários de saúde (ACS) também devem residir nas respectivas áreas de atuação.

\section{Responsabilidades da equipe do PSF}

- As atribuições básicas de uma equipe de Saúde da Família são:

- conhecer a realidade das famílias pelas quais são responsáveis e identificar os problemas de saúde mais comuns e situações de risco aos quais a população está exposta;

- executar, de acordo com a qualificação de cada profissional, os procedimentos de vigilância à saúde e de vigilância epidemiológica, nos diversos ciclos da vida;

- garantir a continuidade do tratamento, pela adequada referência do caso; 
- prestar assistência integral, respondendo de forma contínua e racionalizada à demanda, buscando contactos com indivíduos sadios ou doentes, visando promover a saúde por meio da educação sanitária;

- promover ações intersetoriais e parcerias com organizações formais e informais existentes na comunidade para o enfrentamento conjunto dos problemas;

- discutir, de forma permanente, junto à equipe e à comunidade, o conceito de cidadania, enfatizando os direitos de saúde e as bases legais que os legitimam;

- incentivar a formação e/ou participação ativa nos conselhos locais de saúde e no Conselho Municipal de Saúde.

\section{Os números atuais}

O número de equipes de Saúde da Família continua crescendo: atualmente, até junho último, trabalham 7.991 equipes de Saúde da Família, distribuídas em 2.614 municípios brasileiros, nas 27 unidades federadas, conferindo cobertura a mais de 27,5 milhões de habitantes. Para dezembro desse ano, o Ministério da Saúde e seus parceiros estaduais e municipais trabalham com a meta de implantação de 11.000 equipes.

O modelo garante maior vínculo e humanização da atenção básica mesmo em cidades grandes, onde a relação dos hospitais com os pacientes é fria e nem sempre resolve os problemas de quem os procura. A diversidade é a maior riqueza. Em algumas localidades existem propostas como o uso de terapias não-convencionais - plantas medicinais, homeopatia etc.; em outras, organizam-se grupos de caminhada e apresentações teatrais, por exemplo, sempre buscando-se ações integrais e melhores soluções para a assistência.
Os resultados já observados em todo o país e a potencialidade do Programa Saúde da Família fizeram com que o Ministério da Saúde refletisse a prioridade no seu orçamento. Em 1998, o Programa Saúde da Família/Agentes Comunitários de Saúde recebeu um orçamento de R \$ 218 milhões; em 1999, esse valor subiu para R $\$ 380$ milhões e para o presente ano, $\mathrm{R} \$ 680$ milhões. Esses recursos são transferidos como forma de incentivo aos municípios que implantam o Programa de Agentes Comunitários de Saúde e as equipes de Saúde da Família.

A meta para expansão imediata do Programa já foi anunciada e indica, para 2002, 150 mil agentes comunitários e 20 mil equipes de Saúde da Família.

Em termos percentuais, isso representará o acompanhamento, por essas equipes, de aproximadamente metade da população brasileira. Representa, também, a decisão política de iniciar pela atenção básica a reorientação do modelo de atenção à saúde.

Do ponto de vista político, ressalve-se que esse programa não é um projeto de um gestor, nem mesmo de um governo. Desenvolvido nos três níveis de gestão, sua importância é associada ao impacto identificado no desenvolvimento atual da proposta, pelos administradores setoriais e pela própria população, donde se constata a tendência de sua perenidade, garantindo o permanente avanço na melhoria do modelo de atenção à saúde dos brasileiros.

A relativa novidade do modelo ainda não permite um amplo estudo de índices de impacto dessas ações no quadro sanitário nacional. Já existem, entretanto, muitos indicadores qualitativos, medidos em pesquisas de satisfação dos usuários e quantitativos, como o de índices de coberturas vacinais, aleitamento materno e mortalidade infantil, que permitem inferir as vantagens da presente proposta. 